\title{
O Conceito de Saúde e suas Implicações nas Práticas Psicológicas
}

\author{
Patricia Flores de Medeiros \\ Anita Guazzelli Bernardes \\ Neuza M. F. Guareschi ${ }^{1}$ \\ Pontifícia Universidade Católica do Rio Grande do Sul
}

\begin{abstract}
RESUMO - O artigo objetiva problematizar a relação entre saúde e Psicologia quando abordadas a partir da discussão das práticas discursivas, formas de subjetivação e relações de poder fundamentadas em uma abordagem foucaultiana. A discussão questiona como se conformam determinados modos de subjetivação mediante o dispositivo da saúde no campo das políticas públicas. Pretende-se, com isto, visibilizar como práticas em Psicologia forjam tanto o conceito de saúde no qual se sustentam essas práticas, quanto os sujeitos que são os objetos dessas práticas, enquanto o modo de como esses podem e devem ser pensados. Para percorrer a relação entre Psicologia e Saúde tomamos três eixos que constituem a Psicologia como ciência (razão, inconsciente e psicotécnicas) e procuramos demonstrar como esses eixos possibilitam a emergência da saúde no campo da Psicologia.
\end{abstract}

Palavras-chave: políticas publicas; práticas psicológicas; saúde e produção de subjetividade.

\section{The Concept of Health and its Implication on the Psychological Practices}

\begin{abstract}
This paper aims to analyze the relation between health and Psychology through the discussion on discursive practices, ways of subjectivation and power relations based on a Foucaultian approach. It questions how certain ways of subjectivation obey the standards of the health resources in the field of public policies. Therefore, we intend to show how health concept is constructed by psychological practices. These practices do not only produce the subjects, who are their very objects, but they also produce the way they can and must be thought. In order to understand the relation between psychology and health, we take three theoretical aspects that constitute Psychology as a science (the reason, the unconscious and the psychological instruments) to demonstrate how these aspects make the emergence of health in the field of Psychology.
\end{abstract}

Key words: public policies; psychological practices; health and ways of subjectivation.

O objetivo deste artigo é descrever e analisar o conceito de saúde na Psicologia por meio das práticas psicológicas que o estabelecem. Para tanto, entendem-se práticas psicológicas como práticas discursivas provocadoras de formas de subjetivação na contemporaneidade. Podemos citar, como exemplos de práticas psicológicas, a criação de espaços destinados à saúde: spas, academias de ginástica, programas de qualidade de vida nos espaços de trabalho, unidades sanitárias e centros de atendimento psicossociais. Não queremos dizer que as práticas em saúde, como atividade artificial da condição humana, sejam algo atual. A saúde tornou-se foco de investimentos a partir da Modernidade, edificando-se no capitalismo na forma como a concebemos hoje.

Nossa discussão sobre saúde no campo da Psicologia utiliza o conceito de subjetividade porque, ao falarmos de práticas discursivas, nos referimos a exercícios cotidianos que dizem respeito à relação que o ser humano estabelece consigo mesmo e com o mundo a partir de códigos, regras e normas produzidas socialmente. Ou seja, a saúde, quando pensada pela Psicologia, edifica uma série de regulamentos e modulações que estabelecem o modo como o ser humano deve se relacionar consigo mesmo e com o mundo.

A subjetividade torna-se um eixo de problematizações no campo da Psicologia e, em especial, da Psicologia Social

1 Endereço: Av. Ipiranga, 6681, Prédio 11, $9^{\circ}$, Sala 930, Porto Alegre, RS, Brasil 90619-900.E-mail: nmguares@ pucrs.br na rede pública, pois, o SUS (Sistema Único de Saúde) opera com o conceito de cidadania, dever e sujeito de direito que se conforma, juridicamente, na Constituição de 1988. Isso implica não apenas nova política de saúde, mas novos modos de a saúde produzir subjetividades por meio de práticas que estabelecem valores, como o de cidadania e de sujeito de direitos, a partir de um dever do Estado. Por exemplo, o conceito de cidadania relacionado à saúde, conforme Luz (1991), foi visibilizado mediante o movimento da sociedade civil organizada, no final da década de 1980 , na esteira da Reforma Sanitária. Esta veio reivindicar, no Congresso, políticas sociais que assegurem plenos direitos aos cidadãos: "pela primeira vez na história do país a saúde é vista socialmente como direito universal e dever do Estado, isto é, como dimensão social da cidadania" (Luz, 1991, p. 84). Essa proposição sustenta-se tanto nas discussões da VII Conferência Nacional de Saúde, que inclui em seu relatório a necessidade da participação comunitária, quanto nos desdobramentos da VIII Conferência Nacional de Saúde, que sublinhou a noção de que, para a implantação de uma reforma sanitária, é imprescindível um ambiente democrático onde se encontrem a emergência de novos sujeitos políticos, a liberdade do discenso e o governo dos cidadãos.

Neste texto, ser cidadão e sujeito de direito são formas de subjetividade, formas de viver e de relacionar-se consigo. Mesmo que forjadas em determinado tempo-espaço, 
produzem efeitos nas relações entre saúde, cidadania e estado de direito.

Desse modo, quando elegemos determinado objeto, como, neste caso, a saúde, não o fazemos de qualquer lugar - nós o tomamos a partir daquele território no qual aprendemos a olhá-lo. A saúde, então, passa a ser uma realidade que opera determinados processos existenciais ao mesmo tempo em que só é possível a partir de determinadas operações, de certos campos de conhecimento, nos quais ocorrem transportes, traduções, interpretações, isto é, formas de objetivação que, ao darem sentido a determinados fenômenos, produzem modos de nos relacionarmos conosco.

Quando se enuncia "saúde para todos em 2000", como na Assembléia Mundial de Saúde no ano de 1977, ou "adicionar não só anos à vida, mas vida aos anos" (Paim \& Almeida Filho, 2000, p. 44), implica-se uma outra forma de objetivar a saúde e, por conta disso, de produzir verdades sobre a saúde. A Psicologia entra nessa esteira de problematização à medida que saúde está relacionada não só como algo para todos, mas como produção de vida, que pode ser entendida por condições físicas, psicológicas e sociais, ou seja, os aspectos orgânicos, comportamentais e sociais constitutivos da forma de objetivar o ser humano em um ser biopsicossocial. Por meio da objetivação da saúde - biológica, psicológica e sociológica -, objetiva-se também determinado sujeito, um sujeito tridimensionalizado e, ao mesmo tempo, tripartido: biopsíquicossocial.

A saúde passa a figurar como categoria de análise na Psicologia Social quando esta se volta para os processos de produção em saúde - sejam esses processos formas de conhecimento ou tecnologias de cuidado, prevenção e manutenção da saúde. Desse modo, o presente texto problematiza a relação entre saúde e Psicologia, propondo discutir como se conformam determinados modos de subjetivação mediante o dispositivo da saúde na rede pública. Objetiva-se, a partir disso, perscrutar de que modo as práticas em Psicologia ${ }^{2}$, relativas às políticas públicas, forjam tanto o conceito de saúde no qual se sustentam, quanto os sujeitos que são abordados por elas.

Operamos com a idéia de que saúde não é um objeto que encontramos através dos tempos, independentemente da relação que se tem com ele e do modo como é acessado. Estamos falando de algo que está perenemente sendo forjado: as regras, as ações. Lida-se com algo em movimento, que também produz determinados movimentos. A Psicologia, ao tornar-se parte do dispositivo da saúde, cria ou recrudesce certos modos de viver, forjando subjetividades. O conceito de modos de subjetivação ou formas de subjetividade, no qual se ampara este texto, fundamenta-se nos estudos de Foucault (1998) sobre uma ontologia histórica do presente. Esta diz respeito ao modo como nos tornamos sujeitos de determinadas verdades, ou seja, a maneira como nos subjetivamos. As discussões do autor centram-se nas questões referentes à verdade e à política ou ao saber e ao poder.

A saúde aqui como a entendemos, em termos de relações de saber/poder, não age sobre o indivíduo, mas sobre sua

2 Mediante a Psicologia hospitalar, comunitária, clínica, do trabalho e escolar. Citamos estas como formas de esquadrinhamento no campo da Psicologia, assim como, na Medicina, ocorrem diversas especialidades, podendo contemplar outras. ação. Assim, quando a saúde é definida como uma questão integral, plural, na ânsia de integrar, de tornar o sujeito indivisível, completo, não se está agindo sobre o indivíduo, mas sobre a relação, as ações que ele estabelece consigo e os outros em termos de cuidados e atenção integral. O que se quer apontar é que não existe uma unidade do conceito de saúde, mas formas que o conceito vai assumindo de acordo com os campos que o atravessam. Saúde pode estar ligada às políticas públicas e objetivada como uma questão plural, biopsicossocial, mas também pode estar relacionada ao culto do corpo.

Para percorrer a relação entre Psicologia e saúde, situaremos três eixos que passam a constituir a Psicologia como ciência e as fissuras criadas nesses eixos como espaço para a emergência da saúde no campo da Psicologia. Esses eixos são razão, inconsciente e psicotécnicas. O texto segue certa linearidade, quer dizer, situaremos primeiro o eixo da razão, depois o eixo do inconsciente e, finalmente, o das psicotécnicas. Mas é importante ter claro que essas conformações não são lineares, não ocorrem em seqüência - primeiro uma, depois as outras. Elas são formas que vão se tecendo e se atravessando. Compreendemos que a conformação desses eixos não é um processo de evolução, de desenvolvimento e progresso através dos tempos, mas de acontecimentos, de irregularidades que se engendram em determinados temposespaços, caracterizando uma historicidade desses eixos. Em alguns momentos, um ou outro eixo intensifica-se e exclui os demais; em outros, esses eixos reforçam-se. Queremos dizer que se trata de jogos, de estratégias e movimentos sociais do cotidiano e não uma cronologia de grandes eventos históricos. Esses três eixos, compreendidos como um conjunto de enunciações, visibilidades e relações de força (Deleuze, 1988), são vistos como práticas que se estabelecem no cotidiano. Logo, essas práticas psicológicas, constituídas pelos três eixos, são responsáveis por forjar objetos dos quais passamos a nos ocupar, como aquilo que pode e deve ser pensado, falado, que é o caso das obejtivações da razão, do inconsciente e das psicotécnicas.

\section{A Psicologia e a saúde das populações: organismo e indivíduo}

No que tange ao primeiro eixo - razão -, a Psicologia tornou-se uma disciplina científica por meio das relações que se estabelecem entre Ciências Humanas e práticas sociais no final do século XIX, propondo-se a "descobrir" o que tornava os seres humanos sujeitos da razão. Ou seja, a Psicologia emerge dentro das condições de possibilidade que a episteme da modernidade industrial permitiu. Desse modo, a Psicologia volta-se para a consciência e institui um domínio da razão, dos processos conscientes e cognitivos que permitem ao ser humano saber quem é, de que maneira age e por que age de determinadas formas e não de outras para governar a si mesmo e tornar-se humano, sujeito da razão que difere daquilo que foi o solo de comparação: a espécie animal. Assim, a Psicologia, naquele momento, não tinha como foco a saúde, tampouco a doença.

Mesmo que, como aponta Paim e Almeida Filho (1998), as bases doutrinárias dos discursos sociais sobre saúde tenham aparecido na metade do século XVIII, na Europa 
Ocidental, como um processo de disciplinamento dos corpos e constituição das intervenções sobre os sujeitos, a Psicologia não os entendia desse modo, pois estava voltada para os fenômenos da consciência. As práticas higienistas são alvo do campo da Medicina nesse momento, não se atendo a fatores de ordem psicológica, e sim de higiene social. A higiene, entendida como conjunto de normatizações a serem seguidas e aplicadas em âmbito individual, produz um discurso sobre a boa saúde atrelado à esfera moral. "Foi no biológico, no somático, no corporal que, antes de tudo, investiu a sociedade capitalista. O corpo é uma realidade bio-política. A Medicina é uma estratégia biopolítica" (Foucault, 1995, p. 80).

A higienização do espaço público constituído nos centros urbanos acarreta uma gama de preocupações político-sanitárias. Nesse cenário, começam a proliferar os movimentos higienistas, em que a Medicina figura como ator principal das tecnologias de disciplinamento (conjuntamente com o Estado). A política (polícia) médica estabelece o Estado como definidor de políticas, leis referentes à saúde no coletivo, e como fiscalizador de sua aplicação social, remetendo os discursos e as práticas de saúde à instância jurídico-política (Paim, 1986).

Com a Revolução Industrial, segundo Paim (1986), a saúde passa a ser incorporada nas pautas de reivindicações dos trabalhadores mediante o incremento de sua participação política, principalmente na Alemanha, na Inglaterra e na França, produzindo um impacto sobre as condições de vida e saúde das suas populações. A relação entre condições de vida e saúde das populações cria a necessidade de ações governamentais em termos de controle e organização social, o que provoca a emergência de um campo de ações que passa a ser nomeado de Medicina Social. A Medicina Social resulta desse processo político e social, postulando aplicação da Medicina no campo social, visando à cura dos males da sociedade. Apesar do seu fracasso, fornece as bases doutrinárias para, subseqüentemente, se pensarem as questões de saúde na sociedade.

Paralelamente, nos EUA e na Inglaterra, constitui-se o movimento chamado de Sanitarismo, ligado à questão da ação do Estado na saúde. Esse movimento visava à aplicação de tecnologias e princípios de organização racional para a expansão de atividades profiláticas (saneamento, imunização e controle de vetores) para as classes populares e os setores excluídos da população. Esse conjunto de relações entre saneamento, imunização e controle de vetores encontra no paradigma microbiano a sua justificativa e vem a reforçar o movimento Sanitarista, promovendo as bases do processo de hegemonização, batizado de Saúde Pública, que redefine a teoria e a prática no campo da saúde social no mundo ocidental.

Nessa perspectiva, o que marca o conceito de saúde não é propriamente sua definição enquanto relação com a ausência de doenças, mas o controle preciso das populações no que tange às questões sanitárias e de organização do espaço urbano. Nesses períodos, vislumbra-se o nascimento dos hospitais como tecnologia de controle dos coletivos a partir do esquadrinhamento dos grupos sociais, separando-se a gama de população que coloca em risco o espaço urbano. Não existe efetivamente um investimento em práticas de cura, e sim de isolamento.
Quando a Psicologia funda-se como ciência, em meados do século XIX, encontra como foco de investimentos os processos da consciência e não tem a pretensão de voltarse para discussões e investigações relativas à saúde, pois estabelecia, como condição de investigação, "indivíduos saudáveis". Entretanto, concomitantemente ao processo de constituição da Psicologia como ciência, como uma disciplina, engendra-se, nas sociedades ocidentais, certo modo de organização social do qual começam a proliferar práticas de higiene social (asilos/hospícios). Ou seja, a Medicina entra na esteira do controle social das populações e adota como foco de investimento os processos de saúde e doença dos grupos sociais. É importante dizer que se efetuam ações de controle das populações (natalidade, mortalidade, saneamento, distribuição do espaço urbano). Entretanto, o olhar e os investimentos recaem sobre os indivíduos, pois é mediante o reforço do individualismo, registro das objetivações da modernidade, que as micropolíticas ganham espaço, marcam os corpos e produzem subjetividades.

Como foi ressaltado anteriormente, o primeiro eixo da Psicologia sustentava-se em pesquisas laboratoriais com ênfase nos processos mentalistas, tais como experiência consciente e percepção. A Psicologia não tecia relações com um conceito de saúde ou com o conceito de cura, visto que os processos mentalistas analisados se voltavam para indivíduos sem características de adoecimento. No início do século $\mathrm{XX}$, não encontramos importantes práticas psicológicas voltadas para as afecções da população, mesmo que Wundt (Farr, 1999) tenha realizado um extenso trabalho sobre a sociedade por interessar-se pelos fenômenos da mente em geral e não de um indivíduo isolado (linguagem, religião, costumes, magia). Mas, como esses fenômenos estudados por Wundt não poderiam ser apreendidos em laboratório e tampouco reduzidos ao organismo, essa parte do trabalho do autor foi negligenciada pela Psicologia, que reforçou a noção de indivíduo/organismo. O que fez a Psicologia, por meio de seus estudos laboratoriais, foi estabelecer uma relação entre mente e organismo, dando status de organicidade e individualismo aos processos cognitivos.

\section{Psicologia e a construção de seu sujeito psíquico}

Em relação ao segundo eixo da formação da Psicologia como ciência - o inconsciente -, outro movimento marca as práticas em Psicologia, porém, a partir da formação de um outro território: o da diferença que o sujeito faz de si em relação à razão. Diferença por não se tratar somente do campo da razão como constitutiva do indivíduo, mas de uma região de desconhecimento; diferença em relação a um "eu" consciente de si mesmo, de impossibilidade do governo de si por ferramentas da consciência - produção de sujeitos do inconsciente, sujeitos do desejo. Diferente do que foi apontado no primeiro eixo, não se trata do sujeito que conhece, mas do sujeito marcado pelo desconhecimento, pois é onde o ser humano se desconhece que se torna sujeito e não onde se conhece.

Esse movimento emerge da Medicina, pois seus fundadores principais eram médicos - Freud e Jung. Em estudos produzidos no campo da Medicina, encontramos algumas das condições de existência do sujeito do inconsciente na 
Psicologia. Desse modo, as bases de práticas individualistas no campo da Psicologia encontram-se nas produções das práticas médicas. Freud parte de uma noção de indivíduo - complexo de Édipo - para pensar o coletivo, e Jung parte de uma noção de coletivo - arquétipos - para pensar o indivíduo. Ambos, por sua formação médica, voltam-se para as afecções da alma, para aquilo que não era do organismo, mas que se manifestava no corpo - sintomas.

$\mathrm{Na}$ Psicologia, criam-se tecnologias para o ser humano tornar-se sujeito do desconhecimento, e esse desconhecimento é o que lhe possibilitará tornar-se humano, ou seja, a essência do humano estará no desconhecimento. Em outras palavras, o inconsciente torna-se a região onde se encontra a verdade do sujeito. É nos processos inconscientes e não nos conscientes que se localiza a verdade dos modos de viver. Então, para se desenvolver como humano, para compreender o modo como vive e transformá-lo, são necessárias estratégias de autoconhecimento - um autoconhecimento que se faz por meio de práticas que acessem aquilo que se desconhece de si mesmo. Para tanto, foi necessária a criação da arte de escutar e falar de si, a arte da confissão contemporânea, pois é o Outro que terá a chave do que o próprio sujeito desconhece. Entrase em um jogo de decifração psicológica engendrado, entre outros, pela metáfora edípica, principalmente pelo encontro com a Esfinge.

Nesse contexto, emergem as tecnologias da subjetividade mediante a Psicanálise, e traça-se uma das possibilidades de a Psicologia voltar-se para a saúde por meio da psicopatologia. As tecnologias não são mais uma maneira de se libertar dos pecados da alma, mas um modo de tornar-se um "eu" psicológico, um "eu” que, por meio de análise do inconsciente, se constitui de forma saudável, mesmo que a saúde seja forjada como uma figura neurótica. Apesar de a Psicanálise considerar-se um campo distinto da ciência, da Psicologia e da Medicina, ela surge no escopo da própria Medicina. Isso porque Freud teve a Medicina como formação e focalizou, principalmente, "os transtornos da alma", as psicopatologias, o mesmo que fazia a Medicina, voltando-se para os adoecimentos - mas não os orgânicos, e sim os psíquicos - ao investir, em um primeiro momento, nas subjetividades histéricas que conformavam um certo modo e figura existencial da época.

Rose (2001) salienta que, na modernidade, o indivíduo passa a ser produzido como um "eu”, uma existência singular que marcaria as fronteiras entre uma vida interior - o eu - e o que estaria fora desse território. Encontra-se na Psicologia um dos vetores de constituição desse "eu", tanto na conformação deste como indivíduo (primeiro eixo) quanto na conformação de um sujeito do inconsciente. Trata-se de uma forma de subjetivação pela qual o indivíduo se reconhece e se relaciona consigo mesmo mediante formas de atenção que dirige a si próprio e aos outros. Segundo o autor, quando pensamos em formas de subjetivação, o objeto não é esse "eu”, nem a história desse indivíduo, mas as relações que estabelece consigo mesmo, as práticas, os exercícios pelos quais se relaciona consigo mesmo como "eu", como, por exemplo, na busca por estabelecimentos psicológicos. São jogos, estratégias que colocam em questão os modos de viver, aliás, que engendram os modos de viver a partir de lutas por imposições de sentidos, por conformação de formas existenciais.
Outra questão importante é que as atenções das práticas psicológicas, nos primeiros momentos do século XX, voltamse para os indivíduos que podiam dispor da atenção médica, ou seja, as práticas psicológicas não tinham como objeto a população em geral. Assim, uma das críticas feitas, muitas vezes, à Psicanálise até determinado momento do século, é que ela era fundamentalmente elitista, mesmo que algumas discussões situassem um campo coletivo - Totem e Tabu, Mal-estar da Cultura. Nesse sentido, se as práticas psicológicas no primeiro eixo situam a atenção no indivíduo, mas não em termos de saúde, no segundo eixo, toma-se o conceito de saúde pela Medicina, amparando-se em práticas individuais e não em um conjunto da população ou dos fenômenos de população - epidemiologia.

Os instrumentos que os seres humanos, historicamente, adotam para constituírem a si mesmos são compreendidos, na abordagem deste texto, como produções culturais, práticas de significação, práticas simbólicas, lutas por imposição de sentidos que estabelecem formas de relação do ser humano consigo mesmo, como um "eu", como um indivíduo com uma interioridade. Assim, vemos que é na emergência e na confluência das ciências humanas e naturais, entre elas, a Psicologia, que se edifica um outro conceito de saúde e se modifica a noção de sujeito, noção esta de um sujeito que deve ser considerado de maneira plural na sua relação com o meio ambiente. Nesse caso, quando a Psicologia volta-se para os fenômenos de normalidade e anormalidade, funda uma interioridade em que se encontram as condições para a produção de saúde ou doença. Tal interioridade ganha um campo de exterioridade, pois passa a ser objeto, passa a produzir verdades sobre o sujeito, torna-se uma realidade que precisa ser acessada mediante as tecnologias psicológicas.

Tanto a Medicina quanto a Psicologia, ao focarem a saúde e nela investirem, conformam uma região de interioridade, de privatividade que se encontra no corpo ou na alma/mente, ou seja, tanto uma quanto a outra tornam materializáveis os corpos e as almas/mentes, realidades factíveis, artificiais, no sentido de serem forjadas e de criarem necessidades de investimentos públicos. Ao privatizar a existência quando esta é forjada em uma interioridade, abre-se a necessidade de torná-la pública como possibilidade de controle, de disciplina, de governo. A Psicologia, então, conjuntamente com outros discursos que se voltam para a saúde, promove a noção de que acessar o "eu interior" é um modo de produção de saúde, pois é esse "eu interior" que se encontra em um estado de imperfeição, de incompletude, de incapacidade.

Todavia, deve-se acentuar que não se trata de um movimento da Psicologia para nomear certo estado de incapacidade, de anormalidade, caracterizando uma forma de pensar em que as palavras nomeiam os objetos. Pelo contrário, mediante as práticas discursivas, as ações cotidianas da Psicologia fazem emergir essa realidade de um outro incapaz em sua interioridade. As práticas discursivas encontram-se entre as palavras e as coisas, não existindo uma equivalência entre ambas, e sim o estabelecimento de regras de equivalência que se criam nesse entre a partir de exercícios e de ações no cotidiano.

Essas ações, tecnologias inventadas pela Psicologia como modo de materializar uma interioridade, vão desde as maneiras de protocolar a subjetividade por meio de nosografias, 
pareceres, avaliações, até exercícios comportamentais, como falar de si privadamente ou em grupo, atentar para as próprias condutas, controlar os excessos, responsabilizar-se por seus atos e assim por diante. É lógico que a Psicologia entra na esteira das discussões de que o humano é constituído em seu meio, mas essa perspectiva implica a noção de que existem realidades independentes - humano e meio, indivíduo e sociedade -, incrementando a necessidade de uma atenção integral à saúde.

\section{A Psicologia e o social: a saúde das populações}

O terceiro eixo, caracterizado como psicotécnicas, ampara-se no estreitamento de práticas psicológicas e saúde tecido a partir da Segunda Guerra Mundial. É nesse momento que encontramos matizes do terceiro eixo de práticas em Psicologia: as psicotécnicas. Essas práticas não propõem uma teoria do sujeito, como o da razão e o do inconsciente, mas são, antes de tudo, psicologias aplicadas, tecnologias da subjetividade produzidas a partir do encontro com as formas de administração, de otimização, de adestramento dos corpos. São tecnologias para que os sujeitos sirvam melhor às instituições, que, assim como os produzem, os envolvem de tal forma que eles não mais conseguem "pensar-se", "conhecer-se", "observar-se" sem a mediação desse vetor - as instituições.

Essas tecnologias produzem sujeitos de uma engrenagem, peças que constituirão um todo e, porque se experimentam como parte de um todo, também se experimentam como indispensáveis à manutenção desse todo. São sujeitos operários, alunos, militares que se conformam dentro de instituições de enclausuramento, como as fábricas, as escolas, o exército. São peças de uma engrenagem, pois não são tomados individualmente, mesmo que as técnicas tenham um cunho individual, mas focados e investidos como grupos que devem ser regulados para o aperfeiçoamento. Para o operário ser operário, ele precisa da fábrica; para o aluno ser aluno, ele precisa da escola; para o militar ser militar, ele precisa do exército. Os espaços tornam-se as condições de existência dessas formas de sujeito, sendo imprescindível investir nos corpos como modo de sustentação desses espaços. Os marcadores produzidos nesse eixo dizem respeito às categorias hierárquicas profissionais, intelectuais e econômicas que classificam e organizam os espaços coletivos.

$\mathrm{Na}$ contemporaneidade, encontramos as psicotécnicas aplicadas nos treinamentos, qualificações e capacitações organizacionais com vistas a melhorar a qualidade de vida. O importante dessas técnicas é a edificação do sujeito necessário. Entretanto, há hierarquias, distinção nos graus de profissionalização, que surgem quando se criam classificações - hierárquicas, intelectuais - que utilizam, como critérios, escalas de comparação: mais apto/menos apto; mais inteligente/menos inteligente. Objetiva-se, com as psicotécnicas, o nivelamento dos sujeitos em relação a critérios de normalidade e anormalidade que se aproximam da definição do conceito de saúde como ausência de doença. Nessa esteira, as práticas psicológicas passam a ocupar-se do sujeito trabalhador, tanto nas organizações de trabalho quanto nas comunidades urbanas, formando um sujeito psicológico a partir da noção de funcionalidade, ou seja, é por meio da relação que o sujeito estabelece com seu cotidiano de trabalho que será considerado objeto de práticas e investimentos da Psicologia.

As práticas em Psicologia não focalizaram especificamente o que veio, no século XX, marcar o próprio campo: a diferença no que tange à relação saúde/doença, principalmente no domínio das psicopatologias da alma, da aprendizagem, do trabalho, da pobreza e outros mais que foram inventados como modo de equalização de processos de subjetivação e "biopolitização" dos corpos, tendo em vista reformas sociais, sanitárias, habitacionais. O que se focaliza são ações de cunho individualista e adaptacionista.

Essas ações psicológicas individualistas e adaptacionistas estão na publicação do Relatório Flexner, dos EUA, que redefine o ensino e a prática médica a partir de princípios tecnológicos rigorosos, com bases em uma lógica positivista. Sua ênfase está na pesquisa experimental de base subindividual, geralmente sobre doenças infecciosas. O modelo conceitual flexneriano reforça a separação entre individual e coletivo, privado e público, biológico e social, curativo e preventivo, um processo semelhante ao campo das psicotécnicas: normal/anormal, apto/não apto...

É nesse território que a Psicologia começa a construir um campo de focos e investimentos em que se volta para as populações e, posteriormente, para a saúde desses coletivos. A Psicologia vem a contribuir com pesquisas quantitativas, validadas estatisticamente para classificar, organizar e investir nas populações de modo a estabelecer as bases do desenvolvimento humano e os modos como este deve ser feito por meio de técnicas de cuidados das famílias, dos trabalhadores, enfim, dos conjuntos estabelecidos como focos de atenção.

Segundo Paim e Almeida Filho (1998, p. 301), foi a retomada da proposição de Winslow, datada da década de 1920 , " a arte e a ciência de prevenir a doença e a incapacidade, prolongar a vida e promover a saúde física e mental mediante os esforços organizados da comunidade", que recrudesceu a necessidade de se voltar para as comunidades e nelas investir. Com ela, prescrevem-se quatro tarefas básicas para teoria e prática de uma "Nova Saúde Pública" que orientará o modo como o conceito de saúde passa a ser experimentado: prevenção das doenças não-infecciosas; prevenção das doenças infecciosas; promoção da saúde; melhoria da atenção médica e da reabilitação.

Na década de 1960, encontramos uma mobilização popular em torno de questões sociais: direitos humanos, pobreza, racismo... Nesse momento, a Psicologia começa, efetivamente, a figurar nas comunidades (início da Psicologia Comunitária) e nos Hospitais (início da Psicologia Hospitalar). São movimentos diferentes que marcam a Psicologia, pois, no espaço comunitário, a Psicologia volta-se para os fenômenos da população, em especial daquela com menos acesso aos bens sociais e cuidados à saúde, cujas práticas caracterizam-se enquanto profilaxia ou prevenção das doenças mentais. A inscrição das práticas em Psicologia ocorre mediante a produção de um sujeito psicológico apreendido pelos processos mentais de saúde e adoecimento.

Nos hospitais, a Psicologia abre um campo para trabalhar com a reabilitação de sujeitos que passam por processos cirúrgicos, ampliando-se, posteriormente, para aquilo que configura na contemporaneidade algumas práticas em 
Psicologia - a psicossomática. Assim, estabelece-se que o sujeito psicológico produz formas de afecções orgânicas; portanto, os esforços desse campo voltam-se para a compreensão dos fenômenos psicológicos do indivíduo que o fazem adoecer.

A área da saúde comunitária ou da Medicina comunitária implementa centros comunitários de saúde para efetuarem ações preventivas e cuidados básicos a populações geograficamente definidas. Essa proposta recupera o arsenal discursivo da Medicina Preventiva, principalmente a ênfase nas ciências da conduta (Sociologia, Antropologia e Psicologia). A emergência das ciências da conduta ocorre em virtude da necessidade de ações sobre os modos de viver de populações consideradas vulneráveis. Nesse sentido, as ações preventivas deveriam recair sobre a conduta, sobre as formas de viver das populações como estratégias de controle. O conhecimento dos processos socioculturais e psicossociais não se destina a facilitar a relação médico-paciente ou a gestão institucional como no movimento precedente, mas possibilitar a integração de equipes de saúde nas comunidades problemáticas através da identificação e cooptação de agentes e forças locais para os programas de educação em saúde. $O$ fracasso das ações sobre as populações consideradas vulneráveis é rápido nos EUA, mas, com endosso da OMS, esses princípios passam a fazer parte dos discursos das agências oficiais. Em 1963, órgãos governamentais propõem-se a incluir a participação da população (Paim, 1986).

A Psicologia, como ciência do comportamento, abre e cria um espaço para o controle das condutas e dos comportamentos que possam causar prejuízos à saúde da população e desorganizar os espaços urbanos, contribuindo para conformar o conceito de saúde em relação aos corpos e comportamentos dos indivíduos. Essa inclusão local, nas periferias, levando de certa forma o saber acadêmico aos locais menos favorecidos, vem ao encontro dos modelos preventivos de saúde, nos quais se visa à intervenção nos guetos para diminuir tensões, com uma visão de que a inclusão é feita com a ida de profissionais às comunidades carentes, consideradas problemas não-sociais, visto que o enfoque das práticas médicas/psicológicas acontece sobre os indivíduos dessas comunidades e não nos centros urbanos que produzem essas comunidades periféricas. A Psicologia passa a contribuir com as pesquisas epidemiológicas, mas, agora, com um caráter de epidemiologia psíquica, que contribui para modos de governo das populações.

Na América Latina (Brasil, Chile e Colômbia), devido à atuação da OPS e ao patrocínio de fundações dos EUA, são implantados programas de saúde comunitária. Em 1977, a Assembléia Mundial da Saúde lança, como foi escrito no início do texto, a consigna "saúde para todos no ano 2000" com a política de extensão da cobertura dos serviços básicos de saúde. No ano de 1974, no Canadá, o relatório Lalonde define as bases de um movimento pela promoção da Saúde - "adicionar não só anos à vida, mas vida aos anos" (Paim \& Almeida Filho, 2000, p. 44). Estabelece-se o modelo do campo da saúde composto de quatro pólos: biologia humana; sistema de organização dos serviços; ambiente (social, psicológico, físico); estilo de vida (risco trabalho, padrões de consumo, qualidade de vida).
Em 1978, a Alma Ata - Conferência Internacional sobre atenção primária à saúde - reafirma a saúde como direito do "homem", de responsabilidade política dos governos e intersetorial. É nesse momento que se efetiva a noção de saúde como uma questão de direito que, no Brasil, na década de 1980, tomará consistência jurídico-política com a constituição do SUS, baseada na Constituição de 1988:

A saúde tem como fatores determinantes e condicionantes, entre outros, a alimentação, a moradia, o saneamento básico, o meio ambiente, o trabalho, a renda, a educação, o transporte, o lazer e o acesso aos bens e serviços essenciais; os níveis de saúde da população expressam a organização social e econômica do País (Lei federal, nº 8080/90, art. 3º p. 22).

Nos anos seguintes, constitui-se um projeto nomeado de SILOS - Sistemas Locais de Saúde, com modelo distritalizado -, configurando-se as primeiras iniciativas de reforma setorial de saúde nos países subdesenvolvidos. Essas ações sociais voltadas para a promoção de saúde são sintetizadas na Carta de Ottawa, de 1986, que define o movimento a partir de quatro diretrizes: integração da saúde como práticas de políticas públicas saudáveis; atuação da comunidade na gestão do sistema de saúde; reorientação dos sistemas de saúde; ênfase na mudança dos estilos de vida. É exatamente neste último eixo que a Psicologia vai estar situada enquanto campo de saber que propõe quais poderiam ser esses estilos referentes a uma forma de ser saudável.

Com as psicotécnicas, encontramos um estreitamento das práticas psicológicas que, mesmo oriundas de campos distintos, acabam por reforçar e criar novos recursos para a noção de indivíduo, comportamento e adoecimento. A Psicologia segue na esteira das discussões de saúde da população como modo de politizar suas ações; entretanto, sustenta-se em práticas individualizantes, privatistas e assistencialistas, propondo, por meio de tecnologias psicológicas, o controle das populações.

Assim, vimos que a Psicologia enquanto ciência moderna incita um movimento de privatização da existência e da experiência quando localiza o sujeito em uma dimensão de interioridade do indivíduo - razão e inconsciente -, o que reforça e forja a individualização das existências, pois se foca no indivíduo. Ao mesmo tempo, as psicotécnicas aplicadas investem nas populações por meio de epidemiologias psíquicas que tornam esse indivíduo um objeto público quando considerado em população, tomado em sua dimensão pública de relação com o outro. Nesse sentido, quando forjamos cidadãos psicológicos, o fazemos a partir do campo da Psicologia por meio de uma libertação dessa interioridade considerada constituinte do indivíduo. Então, opera-se tanto na direção de uma privatização da existência quanto de uma publicização de interioridades que devem ser expostas como modo de se ter um cidadão saudável, mas a ênfase está nos indivíduos.

\section{Para finalizar, nos dias de hoje...}

A partir das décadas de 1980 e 1990, edificam-se alguns movimentos que acabam por criar programas acadêmicos, 
programas de modificação de comportamentos de risco, como fumar, sedentarismo, dietas. Além disso, os organismos internacionais estabelecem e determinam o projeto Cidades Saudáveis, da OMS. Em 1991, a OMS atualiza o princípio de promoção de saúde, incorporando a questão do desenvolvimento econômico e social. Saúde passa a ser descrita como um estado de bem-estar físico, psíquico e social, em consonância com as discussões sobre meio ambiente, ou seja, saúde ambiental como prioridade social.

No Brasil, a implantação do Sistema Único de Saúde acarreta uma série de discussões tanto no âmbito epistemológico, quanto no metodológico. As proposições do SUS apontam para a saúde como direito do cidadão e dever do Estado; saúde como uma questão integral; saúde não mais como ausência de doença, mas como uma questão plural; saúde como uma questão coletiva, não pública, à medida que o público remetia a modelos de programas assistencialistas da década de 1960 e 1970; saúde a partir de dados epidemiológicos construídos com a população, e não mais baseada em dados mercadológicos. A Psicologia passa, então, a figurar nas conferências de saúde e nos estabelecimentos da rede pública de saúde, reorganizando as práticas psicológicas tanto no sentido acadêmico e curricular quanto no de mercado de trabalho.

O que é importante enfatizar, aqui, é que não se trata apenas de uma concepção de conhecimento, mas de uma edificação que produziu marcadores na forma de os sujeitos reconhecerem-se e relacionarem-se consigo mesmos, ou seja, as diretrizes de integralidade e interdisciplinaridade propostas pelo SUS criam a necessidade de articulação entre campos de saber distintos na saúde pública - Psicologia, Enfermagem, Nutrição, Fisioterapia, Fonaudiologia, Terapia Ocupacional, Educação Física -, não se restringindo unicamente à Medicina, ao saber médico 3 . "Saúde para todos" ou "todos devemos buscar saúde" são mais do que enunciações no momento em que se tornam uma prática cotidiana, uma ação social para encaminhar indivíduos em direção à saúde, a uma vida com mais saúde, entendendo que esta é tanto biológica quanto psicológica e social.

Quando a Psicologia conforma-se como parte de tratamentos em saúde, por exemplo, no que se refere à qualidade de vida, não se trata apenas de um projeto político, pois implica que abordemos essa possibilidade de relação com o corpo e a existência como uma forma de pensar a saúde. Operam sobre nós mesmos certos modos particulares de existência e de relação conosco que transformam o discurso da saúde em existências saudáveis mediante práticas psicológicas e biológicas.

As políticas públicas em saúde, a partir de considerações de cunho médico, abordam a saúde do corpo enquanto organismo biológico por meio de práticas médicas. Esse discurso, ao encontrar-se com outros, como o da cidadania, da humanização, da atenção integral, formados por distintos campos de saber que encontramos nas políticas de saúde, será complementado, reforçado; em relação a outros discursos, será antagônico (quando se estabelece a saúde como uma questão plural em que outras disciplinas, além da Medicina, passam a operar sobre esse corpo, psicologizando-o: por exemplo, quando a Psicologia começa a trabalhar com a psicossomática). De qualquer forma, acaba por colocar em evidência aquilo que deve ser visto e falado, aquilo do qual devemos nos ocupar na contemporaneidade: a saúde.

\section{Referências}

Foucault, M. (1995). Microfísica do Poder. Rio de Janeiro: Edições Graal.

Foucault, M. (1998). História da Sexualidade II. Rio de Janeiro: Edições Graal.

Luz, M. (1991). Notas sobre as políticas de saúde no Brasil de "transição democrática"- anos 80. Physis: Revista de Saúde Coletiva, 1(1). 77-96.

Paim, J. (1986). Saúde, crises, reformas. Salvador: Centro Editorial e Didático da UFBA.

Paim, J. \& Almeida Filho, N. (1998). Saúde Coletiva: uma "nova saúde pública" ou campo aberto a novos paradigmas? Revista Saúde Pública, 32, (4), 299-316.

Paim, J. \& Almeida Filho, N. (2000) A crise da saúde pública e a utopia da saúde coletiva. Salvador: Casa da qualidade.

Rose, N. (2001) Como se deve fazer a história do Eu? Educação \& Realidade, 26(1), 35-57.

3 A reação médica em relação a esse movimento aparece na contemporaneidade com o Ato Médico, que objetiva regulamentar a ação médica e restringir as ações no campo da saúde ao domínio médico. O Ato Médico encontra espaço para essa regulamentação no próprio "senso comum”, que, ao procurar espaços de atenção à saúde, procura por uma atenção médica. A mudança implica desinstitucionalização da saúde como domínio exclusivamente médico - mudança que abrange tanto usuários quanto trabalhadores da saúde. 